\title{
Childhood abuse and adult-onset asthma among Peruvian women(Article)
}

- Banerjee, D. ${ }^{\text {aEmail Author, }}$

- Gelaye, B. ${ }^{a}$

- Zhong, Q.-Y. ${ }^{\text {, }}$,

- Sanchez, S.E. b,c

- Williams, M.A. ${ }^{a}$

- View Correspondence (jump link)

- $\quad$ Department of Epidemiology, Harvard T.H. Chan School of Public Health, Boston, MA, United States

- $\quad{ }^{\mathrm{b}}$ Asociación Civil PROESA, Lima, Peru

- 'Universidad Peruana de Ciencias Aplicados, Lima, Peru

\section{Abstract View references (33)}

Objective: Childhood abuse has been found to be associated with adult-onset asthma; however, this association has not been studied in low- and middle-income countries with a high burden of gender-based violence, including childhood abuse. We examined the odds of asthma diagnosed at age 18 or older in relation to history of physical and sexual abuse among Peruvian pregnant women. Methods: This cross-sectional study collected demographic characteristics, history of abuse and asthma diagnoses from 3081 pregnant women. Logistic regression procedures estimated adjusted odds ratios and 95\% confidence intervals (aOR, $[95 \% \mathrm{CI}]$ ) for asthma diagnoses in relation to abuse. Results: Overall, $71 \%$ of the women reported a history of abuse ( $<18$ years), and asthma was diagnosed among $2.6 \%$ of the cohort participants. The prevalence of physical only, sexual only and both physical and sexual childhood abuse was 38,8 and $25 \%$, respectively. The history of physical only $(1.16,[0.63-2.17])$, sexual only $(2.11,[0.92-$ 4.84]) or both physical and sexual childhood abuse (1.75, [0.94-3.29]) was positively associated with increased odds of asthma, although the associations were not statistically significant in the multivariate analysis. However, the odds of asthma increased with increasing numbers of abuse events ( $\left.\mathrm{p}_{\text {trend }}=0.01\right)$. Women who reported $\geq 3$ abuse events had an increased odds of asthma (1.88, [1.06-3.34]). Conclusion: Our results do not provide convincing evidence that childhood abuse is associated with asthma among pregnant Peruvian women; however, we were able to demonstrate that an increased number of abuse events are associated with asthma. Further research is required to better understand the effects of abuse on asthma. () 2018 Taylor \& Francis Group, LLC. 


\section{Author keywords}

Economicsepidemiologyquality of life

\section{Indexed keywords}

$\begin{array}{cl}\text { EMTREE } & \begin{array}{l}\text { adultadult diseaseArticleasthmachild abusecohort analysiscross-sectional } \\ \text { medical }\end{array} \\ \text { studydisease associationdisease burdenfemalehumanlife historylow income } \\ \text { terms: } & \text { countrymiddle income countryPeruvianphysical abusepregnant } \\ & \text { womanprevalencesexual abuseviolenceyoung adult }\end{array}$

\section{Funding details}

\section{Funding sponsor}

Eunice Kennedy Shriver National Institute of Child Health and Human Development

See opportunities by NICHD

National Institutes of Health

See opportunities by NIH

\section{Funding}

number

Acronym

R01-HD-

059835

NICHD

NIH

\section{- Funding text}

This research was supported by an award from the Eunice Kennedy Shriver National Institute of Child Health and Human Development (R01-HD-059835). The NIH had no further role in study design; in the collection, analysis and interpretation of data; in the writing of the report; and in the decision to submit the paper for publication. The authors wish to thank the dedicated staf $\mathrm{f}$ members of Asociacion Civil Proyectos en Salud (PROESA), Peru, and Instituto Especializado Materno Perinatal, Peru, for their expert technical assistance with this research.

- ISSN: 02770903

- CODEN: JOUAD

- Source Type: Journal

- Original language: English

- DOI: $10.1080 / 02770903.2017 .1339243$

- Document Type: Article

- Publisher: Taylor and Francis Ltd 